Gazi University
Journal of Science
http://dergipark.gov.tr/gujs

\title{
Effect of Heat Treatment on the Structural Properties and Martensitic Transformation of Ni-26.5at. \% Ta High Temperature Shape Memory Alloy
}

\author{
Koksal YILDIZ* \\ Firat University, Department of Physics, 23119, Elazig, Turkey \\ Highlights \\ - Heat treatment effects were investigated in the Ni-Ta alloy. \\ - Structural properties of the are alloy by changed heat treatment. \\ - Heat treatment affected transformation behaviour of the alloy.
}

\begin{tabular}{l} 
Article Info \\
\hline Received: 23/05/2019 \\
Accepted: 29/11/2020 \\
Keywords \\
\hline Ni-Ta \\
Martensitic \\
Transformation \\
High temperature shape \\
Memory alloy
\end{tabular}

\begin{abstract}
The effect of heat treatment at $450^{\circ} \mathrm{C}, 550^{\circ} \mathrm{C}$ and $650^{\circ} \mathrm{C}$ temperatures for 1 hour on the structural properties and the transformation behaviour of Ni-26.5at. \% Ta high temperature shape memory alloy have been examined by XRD, SEM-EDX analysis and DSC measurements. The SEM-EDX investigations showed that microstructures of all heat-treated alloy samples consisted of Ta-rich $\mathrm{NiTa}_{2}$ precipitate phase and matrix. The XRD results indicated that both numbers and intensities of martensite phase reflections of the alloy highly increased as a result of heat treatment at 650 ${ }^{\circ} \mathrm{C}$. This was indication that the structural properties of the alloy were significantly affected by heat treatment at $650{ }^{\circ} \mathrm{C}$. The thermal measurements revealed that the high temperature shape memory behaviour of the alloy did not changed with heat treatment. However, it was seen that heat treatment performed at $450{ }^{\circ} \mathrm{C}$ caused shifting martensitic transformation temperatures of the alloy and hence transformation hysteresis value of the alloy increased.
\end{abstract}

\section{INTRODUCTION}

Transformation temperatures of conventional shape memory alloys (SMAs), such as Ni-Ti and Cu-based alloys, generally do not exceed $200{ }^{\circ} \mathrm{C}$ and shape memory alloys with transformation temperatures above $200{ }^{\circ} \mathrm{C}$ are required for many applications in advanced technological fields, such as automotive, robotics and space industries [1-3]. Many different SMAs are currently being studied for these purposes [4-6] and the intermetallic $\mathrm{Ni}_{3} \mathrm{Ta}$ compound, which exhibits shape memory behaviour with a martensitic transformation temperature above $300{ }^{\circ} \mathrm{C}$, has become a candidate material in these areas [7]. Thus, in recent years, many researchers have tried to determine the mechanism of shape memory behaviour exhibited by the $\mathrm{Ni}_{3} \mathrm{Ta}$ compound and to examine how different factors, such as third element addition, have an influence on its shape memory behaviour and structural properties. Rudajevova and Pospíšil [8] studied shape memory behaviour of single and polycrystalline $\mathrm{Ni}_{3} \mathrm{Ta}$ alloys by performing dilatometric measurements in non-deformed and pre-deformed states. Biffi et al. [9] investigated the effect of B content on the microstructure and martensitic transformation of this alloy by adding $\mathrm{B}$ element at different ratios to $\mathrm{Ni}_{3} \mathrm{Ta}$ alloy. Kosurokova et al. [10] studied the effect of $\mathrm{Co}$ and $\mathrm{Nb}$ additions on the structural properties and phase transformation characteristics of the intermetallic $\mathrm{Ni}_{3} \mathrm{Ta}$ compound.

The aim of this work was to examine the effect of heat treatment on the morphological and the structural properties and martensitic transformation behaviour of the Ni-26.5at. \% Ta high temperature SMA first time. 


\section{MATERIAL METHOD}

The Ni-26.5at. \% Ta SMA was produced by the arc-melting method [11]. Before heat treatment, ingot was cut in pieces under 3 groups. The cutting samples for thermal, morphological and structural analysis were heat treated at $450{ }^{\circ} \mathrm{C}(\mathrm{NiTa}-450), 550{ }^{\circ} \mathrm{C}(\mathrm{NiTa}-550)$ and $650{ }^{\circ} \mathrm{C}(\mathrm{NiTa}-650)$ for 1 hour under air atmosphere. Surface morphologies and chemical analysis of phases in NiTa-450, NiTa-550 and NiTa-650 samples were investigated by scanning electron microscope (SEM, ZEISS EVO MA10) images and energydispersive x-ray spectrometer (EDS) spectra. The reverse and forward transformation temperatures of samples were determined by differential scanning calorimeter (DSC) measurements taken at a heating/cooling rate of $10^{\circ} \mathrm{C} / \mathrm{min}$ in a nitrogen gas atmosphere via SETERAM TG-DSC-800 system. The structural properties of the samples were realised by x-ray diffractometer (XRD, Bruker Discover D8) using $\mathrm{CuK} \alpha$ radiation at room temperature.

\section{THE RESEARCH FINDINGS AND DISCUSSION}

SEM images of the NiTa-450, NiTa-550 and NiTa-650 samples are displayed in Figure 1. All samples exhibit similar morphological features: small-sized and rarely dispersed precipitate phases in the matrix. The chemical compositions of the precipitates in Figure 1-(a-c) were determined by taking EDX spectra. According to EDX spectra, the precipitates observed in the NiTa-450, NiTa-550 and NiTa-650 samples are of 68.92at. \% Ta, 62.2at. \% Ta and 63.79at. \% Ta contents, respectively. The EDX results has indicated that these small-sized grey precipitates in the NiTa-450, NiTa-550 and NiTa-650 samples is the intermetallic Ta-rich $\mathrm{NiTa}_{2}$ phase as observed in as-homogenized sample [11]. The SEM-EDX analysis also reveal that the all samples do not contain another precipitate phase. Compared with as-homogenized sample, it is clearly seen that the heat treatment at low temperatures for 1 hour do not have a significant effect on the morphological properties of Ni-26.5at. \% Ta high temperature SMA. Differently, the Ta contents in the Ta-rich $\mathrm{NiTa}_{2}$ precipitate phase observed in the heat treated samples are lower than that in as-homogenized sample (75.75at. \% Ta) [11].

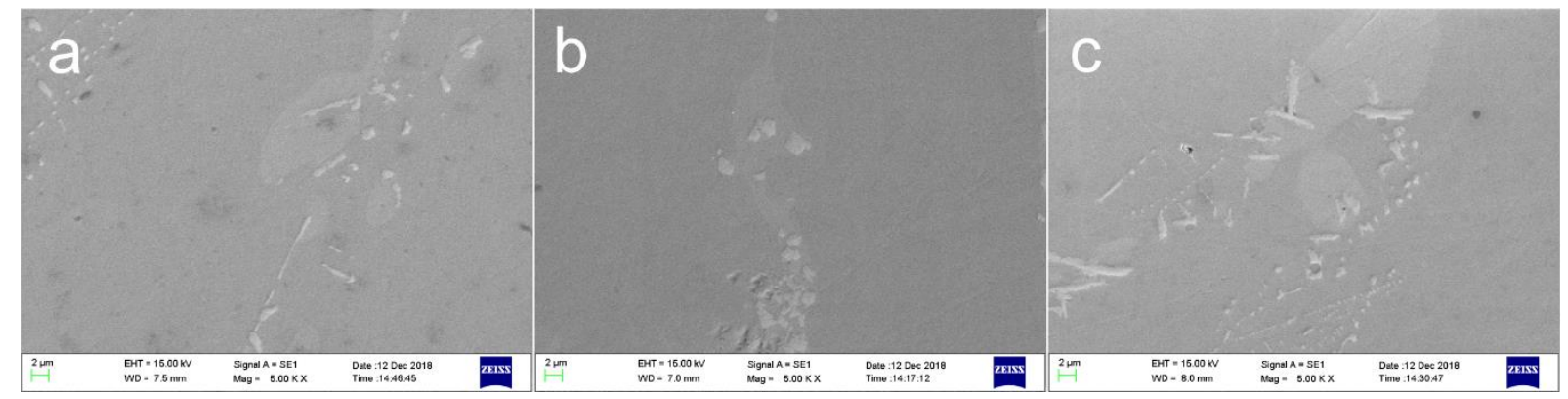

Figure 1. SEM images of (a) NiTa-450, (b) NiTa-550 and (c) NiTa-650 samples

Figure 2 indicates XRD patterns of the as-homogenized [11], NiTa-450, NiTa-550 and NiTa-650 samples. The peaks belonging to the monoclinic martensite (PDF: 01-073-7070) and tetragonal austenite (PDF: 00018-0893) $\mathrm{Ni}_{3}$ Ta phases are indexed on the patterns in Figure 2-(a-d). From Figure 2, it is clearly seen that the heat treatment at low temperatures for 1 hour cause radical changes in the structural properties of the Ni-26.5at. \% Ta high temperature SMA. The main diffraction peak $(004)_{\mathrm{M}} /(112)_{\mathrm{T}}$ located at $2 \theta \approx 42.9^{\circ}$ in as-homogenized sample (Figure 2-a) disappeared completely as a result of the heat treatment at $450{ }^{\circ} \mathrm{C}$ (Figure 2-b) and $550{ }^{\circ} \mathrm{C}$ (Figure 2-c). And also, intensities of $(012)_{\mathrm{M}} /(101)_{\mathrm{T}}$ at $2 \theta \approx 27.62^{\circ}$ and $(-305)_{\mathrm{M}} /(006)_{\mathrm{T}}$ at $2 \theta \approx 76.98^{\circ}$ peaks highly increased in the XRD pattern of NiTa-450 sample, as shown in figure 2-b. In the XRD pattern of NiTa-550 sample shown in Figure 2-c, the intensities of $(-104)_{\mathrm{M}}$ and $(-122)_{\mathrm{M}} /(103)_{\mathrm{T}}$ peaks at $2 \theta \approx 43.36^{\circ}$ and $2 \theta \approx 44.22^{\circ}$, respectively, are higher than the others. However, the most significant changes in the structural properties of Ni-26.5at. \% Ta high temperature SMA occurred in NiTa-650 samples (Figure 2-d). Especially, as can be clearly seen in Figure 2-d, the peak intensities of the monoclinic martensite phase dramatically increased. The main diffraction peak for the NiTa-650 sample is $(201)_{M}$ with reflection at $2 \theta \approx 43.98^{\circ}$. It is understood from the XRD pattern in Figure 2-d that the structural properties and martensitic crystal orientation of the Ni-26.5at. \% Ta high temperature SMA changed significantly as a result of heat 
treatment at $650{ }^{\circ} \mathrm{C}$ compared with other samples. Consequently, due to the peak numbers belonging to the monoclinic martensite phase in Figure 2-d, it can also be claimed that the volume fraction of the martensite phase in NiTa-650 sample has increased. Additionally, there is no diffraction peaks belonging to the intermetallic $\mathrm{NiTa}_{2}$ precipitate phase in the XRD patterns of all samples.

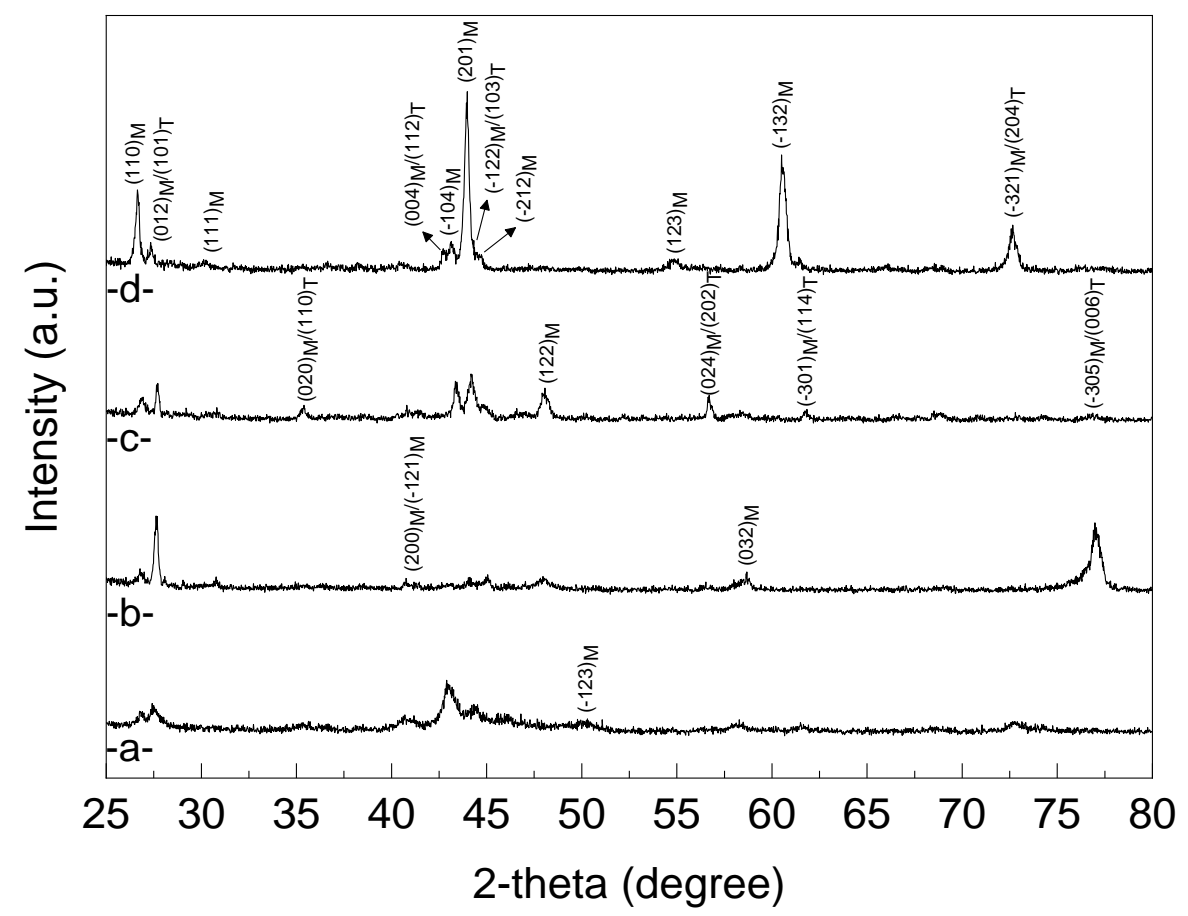

Figure 2. XRD patterns of (a) as-homogenized [11], (b) NiTa-450, (c) NiTa-550 and (d) NiTa-650 samples

The effect of heat treatment performed at different temperatures for 1 hour on the transformation temperatures of the Ni-26.5at. \% Ta high temperature SMA were examined by taking DSC scans on heating and cooling curves. DSC scans of NiTa-450, NiTa-550 and NiTa-650 samples between $150-400{ }^{\circ} \mathrm{C}$ are plotted in Figure 3-(a). Reverse $\left(A_{s}\right.$ and $\left.A_{f}\right)$ and forward $\left(M_{s}\right.$ and $\left.M_{f}\right)$ transformation temperatures of the samples and transformation hysteresis $\left(\mathrm{A}_{\mathrm{f}}-\mathrm{M}_{\mathrm{f}}\right)$ values obtained from the DSC scans in Figure 3-(a) are presented in Table 1. It is known from previous work [11] that the Ni-26.5at. \% Ta alloy exhibits high temperature shape memory behaviour with fully completed martensitic transformation above of $220{ }^{\circ} \mathrm{C}$. However, as can be clearly seen in Table 1 and Figure 3-(b), the heat treatment performed at $450{ }^{\circ} \mathrm{C}$ caused shifting martensitic transformation temperatures of the Ni-26.5at. \% Ta high temperature SMA and as a result of this, martensitic transformation temperature of the alloy decreased below of $200{ }^{\circ} \mathrm{C}$. From this, it has been understood that, among different heat treatment temperatures, the heat treatment temperature of $450{ }^{\circ} \mathrm{C}$ is of the most dramatic effect on the transformation characteristic of the Ni-26.5at. \% Ta high temperature high temperature SMA. Additionally, the NiTa-450 sample possesses higher transformation hysteresis value of $120.2{ }^{\circ} \mathrm{C}$ than those of the NiTa-550 and NiTa-650 samples. On the other hand, the transformation hysteresis values of the all heat treated samples are higher than that of as-homogenized sample [11], as given in Table 1. Herewith, it is obvious that the heat treatment performed at temperatures of $450{ }^{\circ} \mathrm{C}, 550{ }^{\circ} \mathrm{C}$ and $650{ }^{\circ} \mathrm{C}$ lead to increase in the transformation hysteresis of the Ni-26.5at. \% Ta high temperature SMA and this reveals that the Ni-26.5at. \% Ta alloy can have different application areas with performing different heat treatments [12]. 

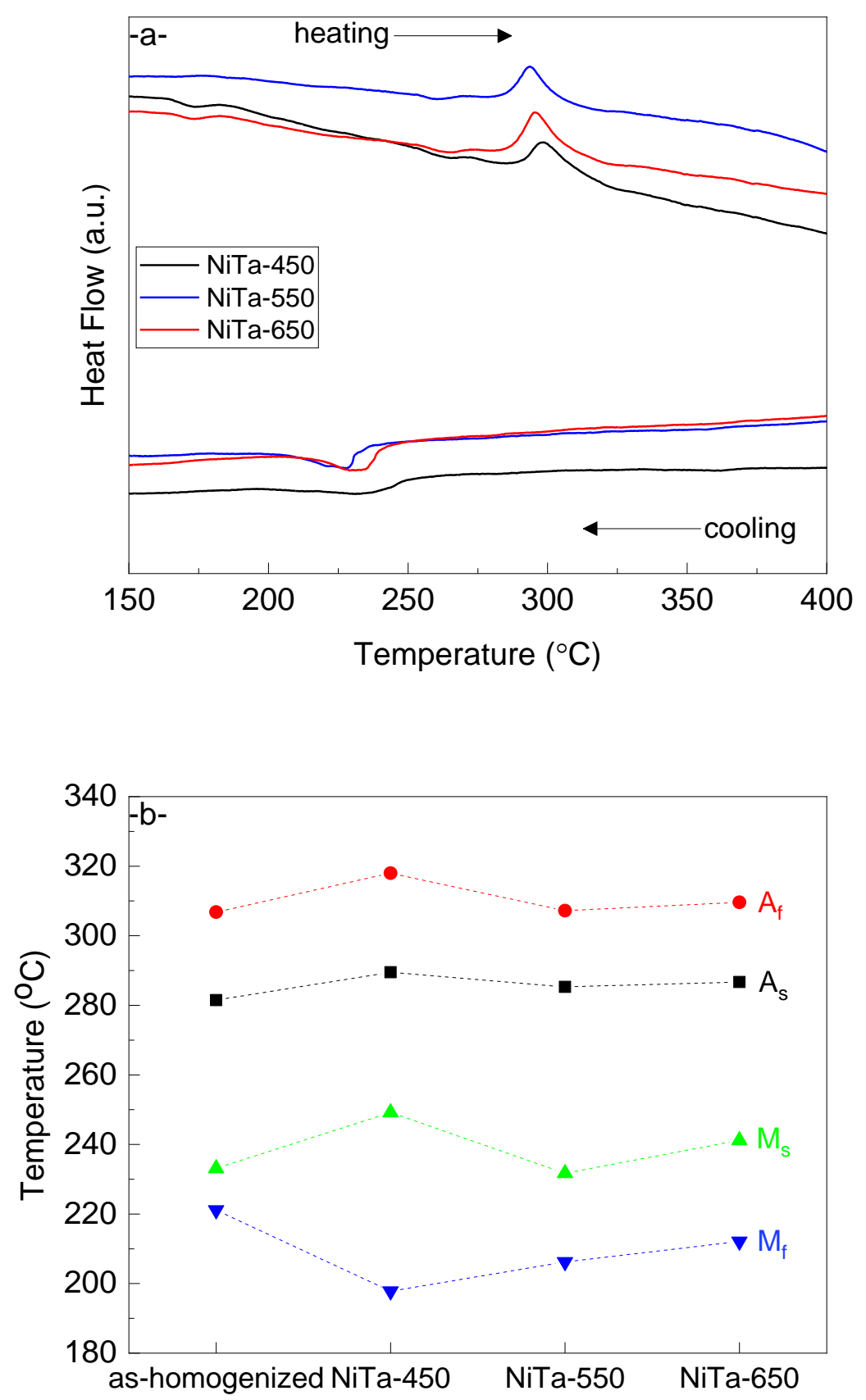

Figure 3. (a) DSC scans of NiTa-450, NiTa-550 and NiTa-650 samples. (b) Variation of transformation temperatures of as-homogenized [11], NiTa-450, NiTa-550 and NiTa-650 samples

In the last years, among many high temperature SMAs, the Ni-Ta alloy has increasing interest and its structural and morphological properties, martensitic transformation behaviour and shape memory effect has been studied depending on its composition [11], by adding third alloying elements $[9,10]$ and under predeformed states $[7,8]$. However, the Ni-Ta alloy system has some disadvantages: cracks in microstructure [7] and tetragonal austenite phase at room temperature with high volume fraction [13]. It has been seen that the crack problems in the Ni-Ta alloy could be tackled with changing homogenization conditions [11]. When examined XRD pattern in Figure 2-(d) belonging to the NiTa-650 sample, it is now though that high volume fraction of austenite phase in the Ni-Ta alloy at room temperature may be decreased with 
performing heat treatments under different conditions, because both the numbers and the intensities of the tetragonal austenite phase reflections in Figure 2-(d) are low compared with those in the XRD patterns of other samples in Figure 2-(a-c). Briefly, it is seen that the heat treatment has a significant effect on the structural properties of the Ni-Ta high temperature SMA, but it is needed further studies in detail.

Table 1. Reverse and forward transformation temperatures and transformation hysteresis values of ashomogenized [11], NiTa-450, NiTa-550 and NiTa-650 samples

\begin{tabular}{llllll}
\hline & $\mathrm{A}_{\mathrm{s}}\left({ }^{\circ} \mathrm{C}\right)$ & $\mathrm{A}_{\mathrm{f}}\left({ }^{\circ} \mathrm{C}\right)$ & $\mathrm{M}_{\mathrm{s}}\left({ }^{\circ} \mathrm{C}\right)$ & $\mathrm{M}_{\mathrm{f}}\left({ }^{\circ} \mathrm{C}\right)$ & $\mathrm{A}_{\mathrm{f}}-\mathrm{M}_{\mathrm{f}}\left({ }^{\circ} \mathrm{C}\right)$ \\
\hline As-homogenized & 281.5 & 306.8 & 233.1 & 221.1 & 85.7 \\
NiTa-450 & 289.5 & 318 & 249.2 & 197.8 & 120.2 \\
NiTa-550 & 285.3 & 307.2 & 231.7 & 206.2 & 101 \\
NiTa-650 & 286.7 & 309.6 & 241.2 & 212.1 & 97.5 \\
\hline
\end{tabular}

\section{RESULTS}

The results obtained from this study can be summarized as below:

- Morphological investigations show that the microstructural features of the Ni-26.5at. \% Ta high temperature SMA are not influenced by heat treatments performed at $450{ }^{\circ} \mathrm{C}, 550{ }^{\circ} \mathrm{C}$ and $650{ }^{\circ} \mathrm{C}$ temperatures for 1 hour. All samples have same microstructural characteristics: the matrix and rarely dispersed intermetallic Ta-rich $\mathrm{NiTa}_{2}$ precipitate in the matrix.

- Structural analysis reveal that the crystallographic properties of the Ni-26.5at. \% Ta high temperature SMA are very sensitive to heat treatment, especially performed at $650{ }^{\circ} \mathrm{C}$. In this heat treatment temperature, it is observed that whereas both the numbers and the intensities of tetragonal austenite phase reflections decrease, those of monoclinic martensite phase reflections increase highly.

- Thermal examinations indicate that the martensitic transformation characteristic of the Ni-26.5at. $\%$ Ta high temperature SMA can be changed depending on heat treatment temperature. With performing heat treatment especially at $450{ }^{\circ} \mathrm{C}$, it is seen that both its martensitic transformation temperatures can be lower and its transformation hysteresis can be wider compared with the others.

\section{ACKNOWLEDGEMENTS}

This work was supported by Scientific Research Projects Coordination Unit of Firat University under Project number: FF.16.36. The author also thanks to Professor Soner ÖZGEN (Firat University) for his technical support under Project number: FF.15.17 and Dr. Fatih SEMERCI (Kirklareli University) for DSC measurements.

\section{CONFLICTS OF INTEREST}

No conflict of interest was declared by the author.

\section{REFERENCES}

[1] Firstov, G.S., Van Humbeeck, J. and Koval, Y.N., "High-temperature shape memory alloys: Some recent developments", Mater. Sci. Eng. A, 378: 2-10, (2004).

[2] Gama, J.L.L., Dantas, C.C., Quadros, N.F., Ferreira, R.A.S. and Yadava, Y.P., "Microstructuremechanical property relationship to copper alloys with shape memory during thermomechanical treatments", Metall. Mater. Trans. A, 37A: 77-87, (2006). 
[3] Celik, H., Aldirmaz, E. and Aksoy, I., "Effects of deformation on microstructure of Cu-Zn-Ni alloy”, GU J. Sci., 25: 337-342, (2012).

[4] Karakoc, O., Hayrettin, C., Evirgen, A., Santamarta, R., Canadinc, D., Wheeler, R.W., Wang, S.J., Lagoudas, D.C., Karaman, I., "Role of microstructure on the actuationfatigue performance of Nirich NiTiHf high temperature shape memory alloys", Acta Mater. 175: 107-120, (2019).

[5] Milhorato, F.R., Mazzer, E.M., "Effects of aging on a spray-formed Cu-Al-Ni-Mn-Nb high temperature shape memory alloy", Mater. Sci. Eng. A, 753: 232-237, (2019).

[6] Paulsen, A., Frenzel, J., Lamgenkämper, D., Rynko, R., Kadletz, P., Grossmann, L., Schmahl, W.W., Somsen, C., Eggeler G., "A kinetic study on the evolution of martensitic transformation behavior and microstructures in Ti-Ta high-temperature shape-memory alloys during aging", Shap. Mem. Superelasticity, 5: 16-31, (2019).

[7] Firstov, G.S., Koval, Yu.N., Van Humbeeck, J. and Ochin, P., "Martensitic transformation and shape memory effect in $\mathrm{Ni}_{3} \mathrm{Ta}$ : A novel high-temperature shape memory alloy", Mater. Sci. Eng. A, 481-482: 590-593, (2008).

[8] Rudajevová, A. and Pospíšil, J., "Shape memory behavior of a $\mathrm{Ni}_{3} \mathrm{Ta}$ alloy pre-deformed in compression”, Mater. Sci. Eng. A, 527: 2900-2905, (2010).

[9] Biffi, C.A., Agresti, F., Casati, R. and Tuissi, A., "Ni3 Ta high temperature shape memory alloys: effect of B addition on the martensitic transformation and microstructure", Mater. Today: Proceedings, 2S: S813-S816, (2015).

[10] Kosorukova, T.A., Firstov, G.S., Koval, Yu.N., Van Humbeeck, J. and Zhuravlev, B., "Phase transformations and shape memory behavior in $\mathrm{Ni}_{3}$ Ta-based intermetallics", Mater. Today: Proceedings, 2S: S793-S796, (2015).

[11] Yildiz, K., "Thermally induced martensitic transformation and structural properties in Ni-Ta high temperature shape memory alloys", Eur. Phys. J. Plus., 134: 11, (2019).

[12] Chen, H.R., Shape Memory Alloys: Manufacture, Properties and Applications, Nova Science Publishers, New York, (2010).

[13] Kosorukova, T., Firstov, G., Noël, H. and Ivanchenko, V., "Crystal structure changes in the $\mathrm{Ni}_{3} \mathrm{Ta}$ intermetallic compound", Chem. Met. Alloys., 6: 196-199, (2013). 